\title{
Solving optimal generation scheduling problem of Microgrid using teaching learning based optimization algorithm
}

\author{
Surender Reddy Salkuti \\ Department of Railroad and Electrical Engineering, Woosong University, Republic of Korea
}

\begin{tabular}{l} 
Article Info \\
\hline Article history: \\
Received Aug 4, 2019 \\
Revised Oct 6, 2019 \\
Accepted Oct 23, 2019 \\
\hline
\end{tabular}

\section{Keywords:}

Battery storage

Demand response

Electric vehicles

Microgrid

Operating cost

Optimal scheduling

Renewable energy

Uncertainty

\begin{abstract}
This paper proposes a new optimal scheduling methodology for a Microgrid (MG) considering the energy resources such as diesel generators, solar photovoltaic (PV) plants, wind farms, battery energy storage systems (BESSs), electric vehicles (EVs) and demand response (DR). The penetration level of renewable and sustainable energy resources (i.e., wind, solar PV energy, geothermal and ocean energy) in power generation systems is increasing. In this work, the EVs and storage are used as flexible DR sources and they can be combined with DR to improve the flexibility of MG. Various uncertainties exist in the MGs due to the intermittent/uncertain nature of renewable energy resources (RERs) such as wind and solar PV power outputs. In this paper, these uncertainties are modeled by using the probability analysis. In this paper, the optimal scheduling problem of MG is solved by minimizing the total operating cost (TOC) of MG. The TOC minimization objective is formulated by considering the cost due to power exchange between main grid and MG, diesel generators, wind, solar PV units, EVs, BESSs, and DR. The successful implementation of optimal scheduling of MG requires the widespread use of demand response and EVs. In this paper, teaching-learning-based optimization (TLBO) algorithm is used to solve the proposed optimization problem. The simulation studies are performed on a test MG by considering all the components of MG.
\end{abstract}

Copyright $@ 2020$ Institute of Advanced Engineering and Science. All rights reserved.

\section{Corresponding Author:}

Surender Reddy Salkuti,

Department of Railroad and Electrical Engineering,

Woosong University, Daejeon, Republic of Korea.

Email: surender.wsu@gmail.com

\section{INTRODUCTION}

Recently with the introduction of power system deregulation and the integration renewable energy resources (RERs), hybrid electric power systems are evolved throughout the world. The hybrid electric power systems incorporate various electricity generating components with usually one major control system which enables the system to supply electricity in the required quality. Components for electricity generation can utilize fossil fuel power plants such as diesel generators, gas turbines, etc. and RERs such as wind turbines, solar photovoltaic (PV), solar thermal, hydro power, tidal power or biomass power stations, etc. With the generation ability using facilities and solutions such as solar PVs, electrical vehicles, energy storage devices, demand response, and other smart devices, the evolvement of conventional consumers to prosumers been receiving increased attention [1]. Microgrid (MG) is the combination of various micro-sources and load demands, which is used to meet the energy crisis, to reduce losses in the system, to provide reliable power supply to critical loads and separates itself from the grid seamlessly without disturbing the load within the network [2].

One of the advantages of MG is that it encourages penetration of RERs for better impact with environment and to reduce emission of carbon dioxide. Therefore, the distributed generation has been introduced in the MG to improve the power quality, for better voltage profile, reduction in losses and 
improved reliability of power supply. An optimal scheduling of energy resources and smart management of loads including smart charging of EVs, DR, and operation of battery energy storage systems (BESSs) for isolated MGs is proposed in Reference [3]. Reference [4] proposes an approach for the assessment of reliability of MG considering EVs and incentive-based DR. An optimal energy management approach for isolated MGs in the presence of DR and BESSs is proposed in Reference [5], and it also examines the controlled and uncontrolled EV charging strategies. A centralized scheduling methodology to exploit demand flexibility from residential devices is proposed in [6]. A distributed charging and discharging scheduling approach for the EVs in MGs is proposed in [7]. A grid-connected MG with PV and a BESS to meet the campus load demand and to minimize the grid dependency is proposed in [8]. A MG model with energy management system based on Model Predictive Control is proposed in Reference [9].

From the above literature review, it is clear that there is a requirement for solving the optimum generation scheduling problem of MG considering various energy resources considering the BESSs, EVs and DR. The wind and solar PV generators can generate and transmit power in the grid-connected or the stand alone mode of MG. Usually, grid connected mode helps to decrease the use of conventional power generation, which results in the lower carbon emission and also plays an important role in global warming. In this paper, it is assumed that the power output from WEG varies according to wind speed, and the wind speed profile at a particular location follows the Weibull distribution. Similarly, the solar isolation effects the power output from solar PV generation system. Generally, the distribution of solar irradiation at a given location closely follows a bimodal distribution, and it is modeled by using Weibull distribution. The main objective of this paper is to find the optimal schedules of MG by optimizing TOC of the system. This TOC function consists of costs due to power exchanged between main power grid and MG, cost due to power output from diesel generators, costs due to power outputs from WEGs, solar PV units, BESSs and EVs. This TOC minimization objective function is solved by using evolutionary based TLBO algorithm. The simulations are performed on a test MG and the results obtained by using TLBO algorithm are also compared with results obtained from EGA. This paper gives the optimal operational set points of solar PV units, WEGs, EVs, BES systems, DR, and it is also useful for regulating the power output of diesel generators.

The remainder of this paper is organized as follows: Section 2 describes the problem formulation of optimal generation scheduling of MG. Section 3 presents the description of TLBO algorithm. Simulation results and discussion is presented in Section 4. Finally, conclusions are presented in Section 5.

\section{PROBLEM FORMULATION}

In this paper, it is assumed that the MG considered is a grid-connected one and it consists of WEGs, solar PV units, diesel generators, DR, BESSs, and EVs. Diesel generator and power exchanged between main grid and MG play a vital role in maintaining stable and reliable operation of MG. Figure 1 depicts the configuration of MG that has been considered in this work.

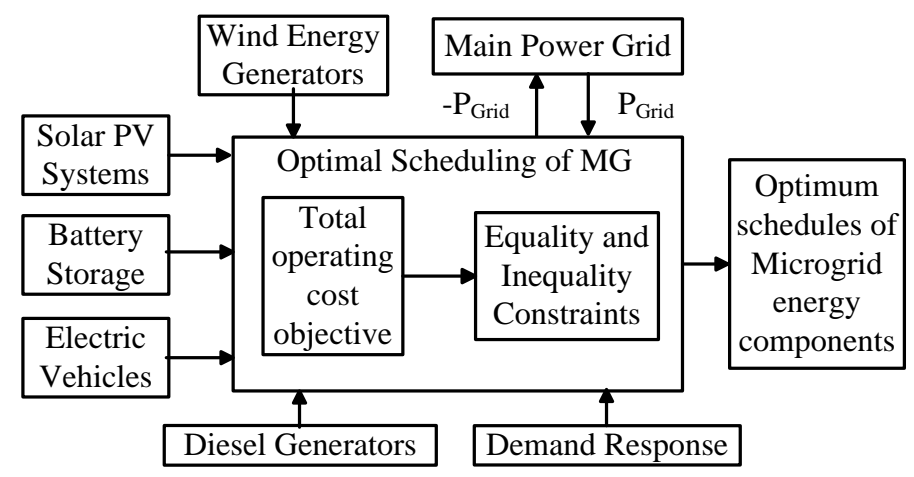

Figure 1. Configuration of microgrid

As mentioned earlier, in this work, minimization of total operating cost (TOC) is considered as the objective function. This TOC is the sum of cost due to power the exchanged between the main grid and the MG, diesel generators, WEGs, solar PV generators, BESSs, EVs and DR [10]. This objective is formulated as,

minimize, 
$T O C=\sum_{t=1}^{T}\left[C_{G r i d}^{t}\left(P_{G r i d}^{t}\right)+\sum_{i=1}^{N_{D G}} C_{D G}^{t}\left(P_{D G, i}^{t}\right)+\sum_{j=1}^{N_{W}} C_{W}^{t}\left(P_{W, j}^{t}\right)+\sum_{k=1}^{N_{P V}} C_{S}^{t}\left(P_{P V, k}^{t}\right)+\sum_{l=1}^{N_{B}} C_{B}^{t}\left(P_{B, l}^{t}\right)+\sum_{m=1}^{N_{E V}} C_{E V}^{t}\left(P_{E V, m}^{t}\right)+\sum_{n=1}^{N_{D R}} C_{D R}^{t}\left(P_{D R, n}^{t}\right)\right]$

Various terms in the above equation are expressed below:

First term is the cost due to power brought from/to main power grid and MG (i.e., $P_{\text {Grid }}^{t}$ ), and it is expressed as [10],

$C_{\text {Grid }}^{t}\left(P_{\text {Grid }}^{t}\right)=C_{\text {Grid }}^{t} \cdot P_{\text {Grid }}^{t}$

Second term is the fuel cost of diesel generators (DGs), and it is expressed as,

$C_{D G}^{t}\left(P_{D G, i}^{t}\right)=\alpha_{i}+\beta_{i} P_{D G, i}^{t}+\gamma_{i}\left(P_{D G, i}^{t}\right)^{2}$

Third term is the direct cost of wind power, and it is expressed as [11],

$C_{W}^{t}\left(P_{W, j}^{t}\right)=d_{j}^{t} P_{W, j}^{t}$

Fourth is the cost due to solar PV power generation, and it is expressed as,

$C_{S}^{t}\left(P_{P V, k}^{t}\right)=e_{k}^{t} P_{P V, k}^{t}$

Fifth term is the operation cost of BESS, and it is expressed as [12],

$C_{B}^{t}\left(P_{B, l}^{t}\right)=C_{B, l}\left(P_{B, l}^{c h, t}+P_{B, l}^{d i s c h, t}\right)$

Sixth term is the cost due to discharge/charge power of EV, and it is expressed as,

$C_{E V}^{t}\left(P_{E V, m}^{t}\right)=f_{E V}^{t} \cdot P_{E V, m}^{t}$

Last term is the cost due to DR, and it is expressed as,

$C_{D R}^{t}\left(P_{D R, n}^{t}\right)=C_{D R}^{t} \cdot P_{D R, n}^{t}$

where $P_{D R, n}^{t}$ is the planned load reduction, $C_{D R}^{t}$ is incentive pay for load reduction. The above objective function is solved subjected to following equality and inequality constraints.

\subsection{Equality Constraints} as [13],

This constraint keeps the balance between power supply and load demand, and it is expressed

$$
\begin{aligned}
P_{i}^{t} & =V_{i}^{t} \sum_{j=1}^{N} V_{j}^{t}\left[G_{i j} \cos \theta_{i j}^{t}+B_{i j} \sin \theta_{i j}^{t}\right] \\
Q_{i}^{t} & =V_{i}^{t} \sum_{j=1}^{N} V_{j}^{t}\left[G_{i j} \sin \theta_{i j}^{t}-B_{i j} \cos \theta_{i j}^{t}\right]
\end{aligned}
$$

where $P_{i}^{t}$ and $Q_{i}^{t}$ are active and reactive powers injected at $i^{t h}$ bus at time t, and they are expressed as [14],

$$
\begin{aligned}
& P_{i}^{t}=P_{\text {Grid }}^{t}+P_{D G, i}^{t}+P_{w, j}^{t}+P_{P V, k}^{t}+P_{B, l}^{t}+P_{E V, m}^{t}+P_{D R, n}^{t}-P_{\text {load }}^{t} \\
& Q_{i}^{t}=Q_{G r i d}^{t}+Q_{D G, i}^{t}+Q_{w, j}^{t}+Q_{P V, k}^{t}+Q_{B, l}^{t}+Q_{E V, m}^{t}+Q_{D R, n}^{t}-Q_{\text {load }}^{t}
\end{aligned}
$$

\subsection{Inequality Constraints}

\subsubsection{Generation Capacity Constraints}

The amount of power bought from/to main power grid is limited by,

$P_{\text {Grid }, t}^{\min } \leq P_{\text {Grid }}^{t} \leq P_{\text {Grid }, t}^{\max }$

Power output from diesel generator is limited by, 
$P_{D G, i}^{\min } \leq P_{D G, i}^{t} \leq P_{D G, i}^{\max }$

Power output from WEG is constrained by [15],

$$
0 \leq P_{w j} \leq P_{r j}
$$

Power output from solar PV unit is constrained by [16],

$$
0 \leq P_{S k} \leq P_{S k}^{\max }
$$

\subsubsection{Constants on Voltages}

The voltages on each bus must be within the range, and they are expressed as,

$$
V_{b, i}^{\min } \leq V_{b, i} \leq V_{b, i}^{\max }
$$

\subsubsection{EV Battery Constraints}

Power output of battery is limited by [17],

$$
-P_{B, l}^{\max } \leq P_{B, l}^{t} \leq P_{B, l}^{\max }
$$

State of charge (SOC) of battery must be within the limits, and it is limited by,

$$
\operatorname{SOC}_{l}^{\min } \leq S O C_{l}^{t} \leq S O C_{l}^{\max }
$$

\subsubsection{Constraints on DR}

The load reduction supported by $n^{\text {th }}$ load demand is expressed as [18],

$$
0 \leq P_{D R, n}^{t} \leq P_{D R, n}^{\max }
$$

The detailed modeling of wind energy system and its uncertainty handling approach is presented in References [19-20]. Reference [21] presents the modeling of solar PV energy system and its uncertainty handling approach. Modeling of BESS is described in Reference [22]. Modeling and uncertainty handling of EVs is described in References [23-24].

\section{TEACHING-LEARNING-BASED OPTIMIZATION (TLBO) ALGORITHM}

In this paper, TLBO algorithm is used for solving the optimal generation scheduling problem of $\mathrm{MG}$ considering the demand response, BESSs and EVs. TLBO is a nature inspired, heuristic and population based optimization, and it is developed to achieve global optimal results. The main difference between TLBO and the conventional optimization techniques is that TLBO gives global minima as solution for the proposed optimization problem [25]. Figure 2 depicts the flow chart of TLBO algorithm.

TLBO consists two methods of learning (i.e., teacher phase and learner phase) in a classroom. Teacher phase is the interaction between learner and teacher. Learner phase is the interaction among the learners. In TLBO algorithm, the number of students (learners) in a class denotes the population, and various constraints represent different subjects taught in the class. Here, teacher of the class represents the learner with best performance, which is measured by problem's fitness value. Hence, the teacher in TLBO is a knowledgeable and learned person, and plays a vital role in improving learner's output (results or grades), and elevating the average level of the class [26]. Improvement in grades of the learner's is done by the combined process of random interaction between the learners and the teacher's input which takes place in the learner phase. Fitness is the learners output in this algorithm. In teacher phase, the existing solution is updated based on mean value, and in learner phase, the learner interacts either among themselves or with good knowledgeable learner to learn new things and to raise the level of their knowledge. The reader may refer References [25-28] for the detailed description of TLBO algorithm. 


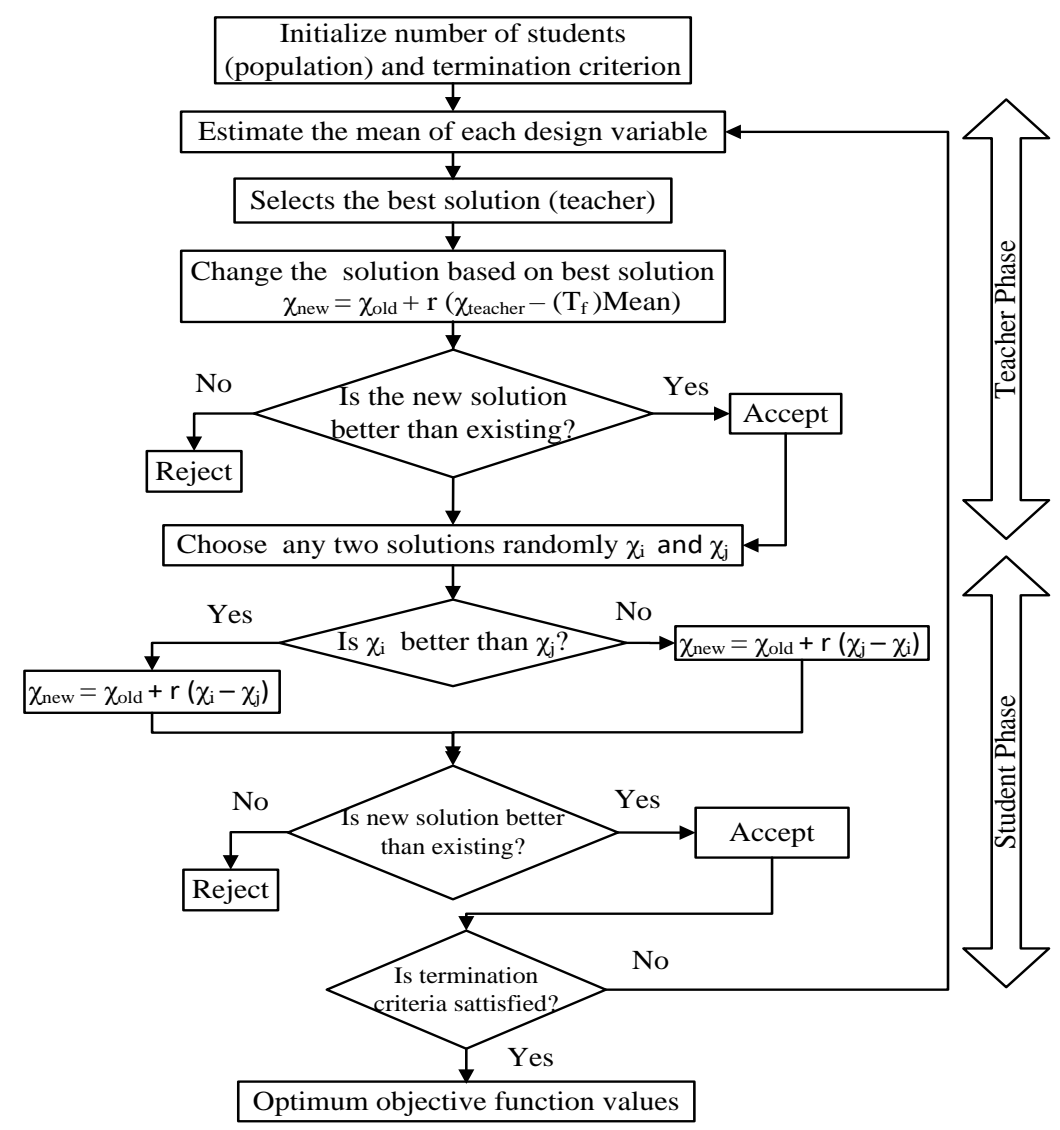

Figure 2. Flow chart of TLBO algorithm

\section{RESULTS AND DISCUSSION}

As mentioned earlier, the MG considered in this work consists of diesel generators, WEGs, solar PV units, BESSs, EVs and DR. All the optimization programs are coded in MATLAB R2018a on a PC with i7 processor, $16 \mathrm{~GB}$ RAM and $3 \mathrm{GHz}$ frequency. Here, the TLBO algorithm is used to solve the proposed optimization problem of optimal generation scheduling of MG. The data required for solving the optimal generation scheduling problem of MG, i.e., solar irradiation data, wind speed data and load demand data for 24 hours period is taken from reference [10]. Here, two different case studies are simulated, and they are:

Case 1: Optimal scheduling of MG considering the power exchange between main grid and MG, and diesel generators.

Case 2: Optimal scheduling of MG considering all the components of MG along with power exchange between the main grid and MG.

The above two cases are solved by considering total operating cost (TOC) minimization as an objective function, and it is solved by using TLBO algorithm, and the obtained results are also compared with enhanced genetic algorithms (EGA). The simulation results for these two cases are presented next:

\subsection{Case 1}

In this case, TOC minimization objective is optimized by considering power exchanged between the main grid and MG, and diesel generators, i.e., other MG components (WEGs, solar PV generators, BESSs, EVs, and DR) are not considered in this case. This TOC minimization function includes only first two terms of objective function (i.e., equation (1)). This objective function is solved by using TLBO algorithm, and the obtained results are reported in Table 1.

The optimum TOC (i.e., best solution) obtained in this case by using TLBO algorithm is $573,102.4$ $\$ /$ day, whereas by using EGA is $573,836.2 \$$ /day. The best, worst and average solutions obtained in this case by using TLBO algorithm and EGA for 50 trials are reported in Table 2 . The best, worst and average solutions obtained in this case by using TLBO algorithm are 573,102.4 \$/day, 575,615.2 \$/day and 573,923.8 $\$ /$ day, respectively. These results show the effectiveness of solutions obtained by using TLBO algorithm compared to EGA for optimal generation scheduling problem of MG. 
Table 1. Objective Function Values for Case Studies 1 and 2

\begin{tabular}{ccccc}
\hline Objective function values & \multicolumn{2}{c}{ TLBO } & \multicolumn{2}{c}{ EGA } \\
& Case 1 & Case 2 & Case 1 & Case 2 \\
\hline Cost of power from main grid and & $573,102.4$ & $44,896.5$ & $573,836.2$ & $44,933.8$ \\
diesel generators (\$/day) & & & & \\
Cost of wind power (\$/day) & --- & $274,582.8$ & --- & $275,088.0$ \\
Cost of solar PV power (\$/day) & --- & $84,958.3$ & --- & $85,065.2$ \\
Cost of BESSs and EVs (\$/day) & --- & $38,960.1$ & --- & $38,964.5$ \\
Cost of demand response (\$/day) & --- & $34,413.5$ & --- & $34,508.1$ \\
Total operating cost (\$/day) & $\mathbf{5 7 3 , 1 0 2 . 4}$ & $\mathbf{4 7 7 , 8 1 1 . 2}$ & $\mathbf{5 7 3 , 8 3 6 . 2}$ & $\mathbf{4 7 8 , 5 5 9 . 6}$ \\
Percentage of cost savings & --- & 16.63 & --- & 16.6 \\
\hline
\end{tabular}

Table 2. Comparison of Results for Cases 1 and 2 using TLBO and EGA Algorithms (for 50 trials)

\begin{tabular}{ccccc}
\hline & \multicolumn{2}{c}{ TLBO } & \multicolumn{2}{c}{ EGA } \\
& Case 1 & Case 2 & Case 1 & Case 2 \\
\hline Best solution (\$/day) & $573,102.4$ & $477,811.2$ & $573,836.2$ & $478,559.6$ \\
Worst solution (\$/day) & $575,615.2$ & $479,048.9$ & $576,133.5$ & $479,980.2$ \\
Average solution (\$/day) & $573,923.8$ & $478,562.7$ & $574,250.6$ & $478,878.4$ \\
\hline
\end{tabular}

\subsection{Case 2}

In this case, the TOC minimization objective is optimized by using TLBO algorithm. As mentioned earlier, in this case, the TOC minimization includes all the terms of objective function (i.e., equation (1)) as this case considers all the components of MG along with power exchanged between the main grid and the MG. Here, the optimum TOC obtained is 477,811.2 \$/day, which is sum of power exchanged between the main grid and the MG, and diesel generators (i.e., 44,896.5 \$/day), cost of wind power (i.e., 274,582.8 \$/day), cost of solar PV power (i.e., 84,958.3 \$/day), cost of BESSs and EVs (i.e., 38,960.1 \$/day), cost of demand response (i.e., 34,413.5 \$/day). In this case, the TOC obtained is $16.63 \%$ less than TOC obtained from Case 1, i.e., cost savings obtained in this case is $16.63 \%$. The results obtained with this TLBO algorithm are also compared with EGA, and they are reported in Table 1. The best, worst and average solutions obtained in this case are reported in Table 2. These results show the effectiveness of solutions obtained by using the TLBO algorithm for the proposed optimal scheduling problem of MG. From the simulation results, it can be observed that the proposed optimal scheduling approach of MG considering the storage, EVs and demand response can effectively improve the flexibility of operation and reliability of MG.

\section{CONCLUSION}

This paper solves a new optimal generation scheduling problem of Microgrid considering various components such as diesel generators, renewable energy resources (wind and solar PV), battery energy storage systems, electric vehicles and demand response. Here, the total operating cost of the system is considered as an objective function, and it is the sum of cost of power to/from main power grid, cost due to wind and solar PV powers, cost of operation of electric vehicles, cost of operation of battery energy storage systems and demand response. The uncertainties involved due to renewable energy resources is handled by using probability distribution analysis. The proposed optimization problem is solved by using teachinglearning-based optimization algorithm. The simulation results on a test Microgrid show the effectiveness of the proposed optimal generation scheduling problem.

\section{ACKNOWLEDGEMENTS}

This research work has been carried out based on the support of "Woosong University's Academic Research Funding - (2019-2020)”.

\section{REFERENCES}

[1] G. Carpinelli, F. Mottola, D. Proto, "Optimal scheduling of a microgrid with demand response resources," IET Generation, Transmission \& Distribution, vol. 8, no. 12, pp. 1891-1899, 2014.

[2] S. Battula, A. Sesetti, H.S.V.S.K. Nunna, S. Doolla, "Multi-agent framework for charging of Plug-in Electric Vehicles in microgrids with demand response," IEEE International Conference on Power Electronics, Drives and Energy Systems, Mumbai, 2014, pp. 1-7.

[3] T. Alharbi, K. Bhattacharya, "Optimal Scheduling of Energy Resources and Management of Loads in Isolated/Islanded Microgrids," Canadian Journal of Electrical and Computer Engineering, vol. 40, no. 4, pp. 284-294, 2017. 
[4] Y. Linhao, W. Ke, C. Xu, H. Tingcheng, L. Mengying, "Reliability Evaluation of Microgrid Considering Electric Vehicles and Demand Response," International Conference on Power System Technology, Guangzhou, 2018, pp. 1668-1672.

[5] T. Alharbi, K. Bhattacharya, "Optimal energy management and smart charging of PEVs in isolated microgrids," IEEE Electrical Power and Energy Conference, London, ON, 2015, pp. 169-176.

[6] S. Gottwalt, J. Gärttner, H. Schmeck, C. Weinhardt, "Modeling and Valuation of Residential Demand Flexibility for Renewable Energy Integration," IEEE Transactions on Smart Grid, vol. 8, no. 6, pp. 2565-2574, Nov. 2017.

[7] T.N. Le, B.J. Choi, H. Liang, H. Li, X.S. Shen, "DCD: Distributed charging and discharging scheme for EVs in microgrids," IEEE International Conference on Smart Grid Communications, Venice, 2014, pp. 704-709.

[8] M.R.B. Khan, J. Pasupuleti, J. Al-Fattah, M. Tahmasebi, "Optimal Grid-Connected PV System for a Campus Microgrid", Indonesian Journal of Electrical Engineering and Computer Science (IJEECS), vol. 12, no. 3, pp. 899-906, Dec. 2018.

[9] M.R.B. Khan, J. Pasupuleti, J.A. Fattah, M. Tahmasebi, "Energy management system for PV-Battery microgrid based on model predictive control", Indonesian Journal of Electrical Engineering and Computer Science (IJEECS), vol. 15, no. 1, pp. 20-25, Jul. 2019.

[10] S.R. Salkuti, "Optimal Operation of Microgrid considering Renewable Energy Sources, Electric Vehicles and Demand Response," 1st International Conference on Sustainable Energy and Future Electric Transportation, E3S Web of Conferences, vol. 87, pp. 1-6, 2019.

[11] S.S. Reddy, "Day-ahead thermal and renewable power generation scheduling considering uncertainty", Renewable Energy, vol. 131, pp. 956-965, Feb. 2019.

[12] S.S. Reddy, J.Y. Park, C.M. Jung, "Optimal Operation of Microgrid Using Hybrid Differential Evolution and Harmony Search Algorithm", Frontiers in Energy, vol. 10, no. 3, pp. 355-362, Sept. 2016.

[13] S. Hadayeghparast, A.S. Farsangi, H. Shayanfar, H. Karimipour, "Stochastic Multi-objective Economic/Emission Energy Management of a Microgrid in Presence of Combined Heat and Power Systems," IEEE/IAS 55th Industrial and Commercial Power Systems Technical Conference, Calgary, AB, Canada, 2019, pp. 1-9.

[14] S. Bracco, F. Delfino, R. Procopio, M. Rossi, M. Robba, "A model predictive control approach for the optimization of polygeneration microgrids and demand response strategies," IEEE 16th International Conference on Environment and Electrical Engineering, Florence, 2016, pp. 1-6.

[15] N. Karthik, A.K. Parvathy, R. Arul, S. Baskar, "A review of optimization techniques applied to solve unit commitment problem in microgrid", Indonesian Journal of Electrical Engineering and Computer Science (IJEECS), vol. 15, no. 3, pp. 1161-1169, Sept. 2019.

[16] T.D. Thanh, Q.N. Phung, H.N. Duc, "Stochastic control for optimal power flow in islanded microgrid", International Journal of Electrical and Computer Engineering (IJECE), vol. 9, no. 2, pp. 1045-1057, Apr. 2019.

[17] Md.A. Zaman, Md.H. Rahaman, Md.S. Reza, Md.M. Islam, "Coordinated Control of Interconnected Microgrid and Energy Storage System", International Journal of Electrical and Computer Engineering (IJECE), vol. 8, no. 6, pp. 4781-4789, Dec. 2018.

[18] I.N. Jiya, N. Gurusinghe, R. Gouws, "Hybridisation of battery, supercapacitor and hybrid capacitor for load applications with high crest factors: a case study of electric vehicles", Indonesian Journal of Electrical Engineering and Computer Science (IJEECS), vol. 16, no. 2, pp. 614-622, Nov. 2019.

[19] J. Hetzer, D.C. Yu, K. Bhattarai, "An Economic Dispatch Model Incorporating Wind Power," IEEE Transactions on Energy Conversion, vol. 23, no. 2, pp. 603-611, Jun. 2008.

[20] S.S. Reddy, J.A. Momoh, "Realistic and Transparent Optimum Scheduling Strategy for Hybrid Power System," IEEE Transactions on Smart Grid, vol. 6, no. 6, pp. 3114-3125, Nov. 2015.

[21] S.S. Reddy, "Optimization of renewable energy resources in hybrid energy systems," Journal of Green Engineering, vol. 7, no. 1, pp. 43-60, 2017.

[22] M. Khalid, "Wind Power Economic Dispatch-Impact of Radial Basis Functional Networks and Battery Energy Storage," IEEE Access, vol. 7, pp. 36819-36832, 2019.

[23] M. Meiqin, S. Shujuan, L. Chang, "Economic analysis of the microgrid with multi-energy and electric vehicles," 8th International Conference on Power Electronics - ECCE Asia, Jeju, 2011, pp. 2067-2072.

[24] J. Wu, Z. Wu, F. Wu, X. Mao, "A power balancing method of distributed generation and electric vehicle charging for minimizing operation cost of distribution systems with uncertainties," Energy Science and Engineering, vol. 5, no. 3, pp. 167-179, Jun 2017.

[25] B. Bhattacharyya, R. Babu, "Teaching Learning Based Optimization algorithm for reactive power planning," International Journal of Electrical Power \& Energy Systems, vol. 81, pp. 248-253, Oct. 2016.

[26] A. Akin, I. Aydogdu, "Optimum design of steel space frames by hybrid teaching-learning based optimization and harmony search algorithms," $17^{\text {th }}$ International Conference on Structural Engineering, Paris, France, vol. 17, Jul. 2015, pp. 1486-1493.

[27] R.V. Rao, V.J. Savsani, D.P. Vakharia, "Teaching-learning-based optimization: A novel method for constrained mechanical design optimization problems", Computer-Aided Design, vol. 43, no. 3, pp. 303-315, Mar. 2011.

[28] B. Mohanty, S. Tripathy, "A teaching learning based optimization technique for optimal location and size of DG in distribution network," Journal of Electrical Systems and Information Technology, vol. 3, no. 1, pp. 33-44, May 2016. 